\title{
Prolegômenos Schmittianos à energia política: Soberania, Legitimidade, Representação
}

\author{
Schmittian Prolegomena to Political Energy: Sovereignty, \\ Legitimacy, Representation
}

\begin{abstract}
Michael Marder ${ }^{[a] b b^{*}}$
[a] Ikerbasque, Departamento de Filosofia, Universidade do País Basco (UPV-EHU), Espanha

[b] Instituto de Humanidades, Universidade Diego Portales (UDP), Santiago, Chile
\end{abstract}

\section{Resumo}

Neste texto, tracei caminhos de pensamento sobre a energia especificamente política baseado nos escritos de Carl Schmitt. Fora do paradigma da ciência natural - nomeadamente da física - proponho-me contrastar a energia política com o poder, retraçando as linhas da oposição aristotélica entre energeia e dunamis. Do mesmo modo, na teoria constitucional schmittiana, "a constituição absoluta" encontra-se do lado da plenitude energética, enquanto a "constituição relativa" baseia-se na força da potencialidade e numa perpétua escassez inerente ao fenómeno da entropia. Finalmente, reformulei a

* MM: Doutor, e-mail: michael.marder@gmail.com 
crítica de Schmitt da democracia representativa parlamentar em termos de uma energia emprestada que separa obras políticas, ou instituições, dos trabalhos que as animam. Consequentemente, defendo que é possível repensar o político como energia, para além das associações tradicionais de poder, força e violência.

Palavras-chave: Energia. Schmitt. Le Bon. Constituição. Representação. Poder. Dunamis. Energeia.

\section{Abstract}

In this text, I outline ways of thinking about the specifically political energy based on the writings of Carl Schmitt. Outside the paradigm of natural science - notably of physics - I propose to contrast sovereign energy to power, retracing the lines of the Aristotelian opposition between energeia and dunamis. Likewise, in Schmittian constitutional theory, "absolute constitution" leans on the side of energetic fulfillment, while "relative constitution" relies on the force of potentiality and a perpetual dearth inherent to the phenomena of entropy. Finally, I recast Schmitt's critique of representative parliamentary democracy in terms of a borrowed energy that separates political works, or institutions, from the workings that animate them. As a result, I argue that it is possible to rethinking the political as energy, beyond the traditional associations of power, force, and violence.

Keywords: Energy. Schmitt. Le Bon. Constitution. Representation. Power. Dunamis. Energeia.

\section{I-Introdução}

Ao abordar o tópico da energia política, o primeiro impulso é contrabandear os conceitos, correlações e axiomas das ciências físicas para as ciências sociais. Poder-se-ia perguntar, por exemplo, como é que as leis da termodinâmica suportam as flutuações da força, causando

1 Trad. portuguesa: Alexandre Franco de Sá. 
segregação entre e agregação dentro de formações antagonísticas de grupos humanos. Escusado será dizer, esta metodologia sucumbiria a um estrito determinismo científico.

Curiosamente, o sociólogo francês Gustave Le Bon desenvolveu a sua pesquisa na direção inversa. Depois da publicação do seu popular tratado sobre a "psicologia da multidão", Psicologia da multidão, em 1895, ele ficou fascinado com a física e publicou $A$ evolução da matéria e A evolução das forças na primeira década do século XX. De acordo com Le Bon, a multidão é a matéria a partir da qual podem ser esculpidas entidades sociais e políticas, e a matéria enquanto tal é um conglomerado temporário que sofre uma dissolução gradual e um declínio. A "mente coletiva" transitória da multidão explode com uma força violenta e é incitada à ação quando a personalidade consciente dos seus participantes se desvanece momentaneamente (LE BON, 1896, p. 2). Com a mesma facilidade, ela volta a cair nos seus constituintes individuais. Infringindo a primeira lei da termodinâmica, matéria e energia não gozam "o privilégio da imortalidade": elas "também têm de entrar no ciclo das coisas condenadas a envelhecerem e morrerem" (LE BON, 1908, p. 10). Tudo menos um pacífico crepúsculo de entropia, a divisão da matéria ao nível sub ou intra-atómico resulta na libertação de largas quantidades de energia armazenadas no átomo, o seu "colossal armazém" (LE BON, 1908, p. 68). Traçando implicitamente um paralelo entre o colapso da consciência individual e a explosão de ação inconsciente coletiva, a física de Le Bon é uma extensão da sua teoria social, e não vice-versa.

Várias décadas depois, Carl Schmitt irá inferir a energia política de fenómenos políticos análogos da física pré-einsteiniana, onde matéria e energia são tratadas como separadas. Apesar de não usar abertamente o termo, o político, para ele, não é matéria, mas energia, não substância, "mas apenas o grau de intensidade [Intensitätsgrad] numa associação ou dissociação de seres humanos". Segue-se que, enquanto pura intensidade ou diferencial de forças, "o político pode derivar a sua energia dos mais variados fatores humanos, do religioso, econômico, moral e outras antíteses" (SCHMITT, 1996a, p. 38). 
A versão de Schmitt da energia política é uma forma dinâmica, o dinamismo da formação, potencialmente nunca satisfeita com qualquer instanciação concreta e independente do seu substrato material. Enquanto houver duas superfícies que, em fricção uma com a outra, chocarem com bastante força, voarão fagulhas políticas. Sem estar ligado a um único domínio substancial, a política prospera na energia de superfícies opostas que Schmitt, sem se interessar pelo seu verdadeiro conteúdo, denomina amigos e inimigos. É absolutamente superficial, livre de uma essência profunda, animado pela exterioridade da inimizade (mesmo que o inimigo seja encontrado dentro de uma dada unidade política) o que põe uma associação humana num curso de colisão com outra. A energia política é elétrica, com as cargas positiva e negativa da inimizade e inimizade empurrando e puxando uma contra a outra num campo previamente neutro, apolítico, que elas perturbam.

\section{II.}

Mas a física da energia política não é, de todo, a história toda. Na medida em que mantém a soberania, toda a entidade política retém o direito de "decidir sobre a distinção amigo-inimigo e, se necessário, fazer guerra" (SCHMITT, 1996a, p. 38). Concordar com a avaliação de que a própria distinção está diretamente dentro da visão do panorama físico (moderno) sobre a energia não quer dizer que a decisão acerca desta distinção pertença ao mesmo panorama. Muito se disse desse decisionismo soberano, o qual, não estando sob regras, cheirava a teológico, primeiro e sobretudo na própria apreciação de Schmitt. Dito isto, a assunção de que qualquer coisa que não obedeça às leis mecânicas, eletromagnéticas ou atómicas transpostas para a vida política é irracional falha redondamente. Ciência ou magia: tal é uma falsa alternativa. A soberania é experimentada como uma irrupção miraculosa, stricto sensu, a partir de dentro do paradigma cientificamente determinista da coexistência humana. A nossa falência torna-se flagrante no momento em que nos preparamos para pagar pela soberania com a moeda da lei 
natural ou das ciências sociais para as "cabeças" e do poder sobrenatural para as "caudas".

Com poucas exceções, não temos problemas com a atribuição dos eventos à causalidade física ou, quando a sua lei não se aplica, a causas metafísicas ou teológicas. Contudo, ao estabelecer assim de forma limitada o nosso pensamento, também negligenciamos outra energia, nem inteiramente imanente nem transcendente em relação a uma dada ordem onde ela se anuncia. A grade macia da legalidade funciona de uma maneira semelhante às relações de causa-efeito na física clássica. No entanto, a energia da legitimidade é irredutível às operações causais que põe em movimento nestas sociedades que, pelo menos nominalmente, respeitam o império da lei. A energia soberana, produzindo decisões sobre quem é um amigo e quem é um inimigo, ou, priore loco, decidindo optar sobre a exceção, põe em ação uma ordem política particular, ativa ou fá-la atuar, embora não seja explicável nos termos daquilo que ativou. A definição do soberano como "quem decide sobre a exceção [wer über den Ausnahmezustand entscheidet]" (SCHMITT, 1985 , p. 5) significa essencialmente que uma exceção decide sobre a exceção, conduzindo uma energia duplamente singular que não pode ser enquadrada com a ideologia da igualdade formal prevalecente nas sociedades democráticas liberais. Talvez só a física quântica se pode ainda encaixar com o ponto zero da energia soberana, solicitando uma aproximação infinita em que a singularidade da exceção soberana funcionaria como um buraco negro do pensamento político.

Não obstante o seu veemente catolicismo, Schmitt está de acordo com Kierkegaard, um "teólogo protestante que demonstrou a necessidade vital possível na reflexão teológica" (SCHMITT, 1985, p. 15), no que respeita ao método de pensar o começo geral a partir da exceção. Ele repete, com prazer e aprovação, as palavras de Repetição: “[...] o geral não é pensado com paixão, mas com uma superficialidade confortável. A exceção, por outro lado, pensa o geral com paixão enérgica [Die Ausnahme dagegen denkt das Allgemeine mit energischer Leidenschaft]" (citada em SCHMITT, 1985, p. 15). Paixão e pathos, passividade e energia, podem ser reconciliados: passar pelo sofrimento e demorar-se com a singularidade produz mais energia que alguma vez poderia produzir 
uma generalização ativa. As decisões soberanas e pensar sobre a soberania são ilegítimos a não ser que experimentem a exceção, que se carreguem com o seu insuportável peso e que recebam a energia esvaindo-se da sua fronteira ou limite exterior - o peras da ex-periência. O soberano não é uma fonte ativa, original, omnipresente da política sob a influência inabalável da metafísica, um suplemento de poder ou uma causa transcendental que acrescenta sentido, vida e morte. A energia soberana, mais do que o poder, gira em torno da passividade para além do binário de atividade e passividade, um ser excluído que, mais tarde, ressoará com a exceção, com base na qual serão tomadas decisões. $\mathrm{O}$ soberano está decidido à existência pela decisão sobre a exceção, estando a energia da legitimidade a rodopiar num círculo estranho ao pensamento da legalidade.

\section{III.}

A teoria constitucional de Schmitt, de modo similar, está compreendida por dois regimes de energia, dois planos tectónicos políticos, correspondendo aproximadamente aos modelos energéticos físico e biológico. O primeiro baseia-se muito fortemente na comparação entre constitucionalismo e entropia, sendo que a decisão original sobre a forma da existência política perde a sua energia nos seus próprios resultados. A formalização é a condição prévia de uma existência ou coexistência minimamente organizada, assim como um precursor de um final entrópico, "a dissolução da constituição unificada numa multidão de leis constitucionais individuais, formalmente equivalentes" (SCHMITT, 2008, p. 67). Aquilo que para Hegel era um momento necessário de mediação, de uma unidade simples e abstrata que se perde a si mesma na multiplicidade apenas para se encontrar numa forma mais concreta, negada determinadamente, é para Schmitt um lamentável relativizar da vida política. A aporia da energia constitucional é que ela imediatamente diminui e se torna impossível em tudo aquilo que ela torna possível, evaporando-se daquilo que ele põe em ação. A força de lei - fragmentada em muitos estatutos legais, por mais que 
sejam fundamentais - despoja a energia política da sua vitalidade. A dunamis da legalidade faz o contrapeso da energeia constitucional.

O outro regime de energia é evidente no "conceito absoluto de constituição", o qual combina "a maneira concreta da existência que é dada com toda a unidade política" e "o princípio da emergência dinâamica da unidade política, de um processo de formação constantemente renovada e emergência desta unidade a partir de um poder e energia fundamentais ou, em última análise, efetivos. [...] A constituição é o princípio ativo de um processo dinâmico de energias efetivas [das aktive Prinzip eines dynamischen Prozesses wirksamer Energien]" (SCHMITT, 2008 , p. 59, 61). Em contraste com a constituição relativa e fragmentada, a constituição absoluta é a constituição constituída, a constituição constituinte e a relação entre as duas: o trabalho, o trabalhar e fazer trabalhar a vida política. Ela mobiliza o descanso e o movimento, o ser e o devir, a existência de uma política e a sua formação, unidade e unificação. "A estrita separação entre o estático e o dinâmico tem alguma coisa de artificial e violento", acrescenta Schmitt (SCHMITT, 2008, p. 65). Ou, noutros termos, a passagem da atividade à atualidade, do trabalhar ao trabalho, é integral para a energia. Toda a constituição que é, que faz ser, e que devém recria-se a si mesma numa luta contra a entropia, semelhante a um ser vivo cujo envelhecer, no entanto, não é de modo nenhum equivalente à perda entrópica.

A homologia entre unidades políticas e organismos, latente no "conceito absoluto" da constituição, claro está, não é novo. Ele remonta, através de Hegel e de Hobbes, a Aristóteles e Platão, que se mantiveram a par da vida própria das entidades políticas. A inovação de Schmitt encontra-se em justapor os tipos físico-inorgânico e biológico-orgânico de energia num enquadramento constitucional que envolve ambos e que assim nos obriga a executar um árduo ato de equilíbrio, enganando uma multiplicidade de leis formalizadas e a existência política, os estatutos estáticos e as decisões dinâmicas, as alianças e as fações beligerantes. Para não nos deixarmos levar, a separação entre estas facetas, como Schmitt nos lembra, é "artificial e violenta". Cada extremo é indispensável para uma energeia política que, ao agir, age contra si, divide-se a si mesma. $\mathrm{O}$ fazer trabalhar a política desencadeia 
antagonismos extremos, destilados a partir das antíteses que estruturam diversas esferas da vida. Mas o que permite à própria política ser política se não a sua revolta contra si mesma, o seu desdobrar-se e tornar-se uma inimiga de si mesma? A despolitização é a mais elevada possibilidade do político, a aparente diminuição da sua energia - o seu maior afluxo. Para especular: só a feroz aversão de Schmitt ao liberalismo podê-lo-ia ter cegado diante desta patente ramificação dialética do seu pensamento político.

IV.

O subtexto saturado de energia dos escritos de Schmitt abre uma prometedora avenida para compreender a questão da representação política. Mantendo a hipótese da entropia, a representação vive de energia emprestada, aproveitando constantemente a fonte oculta da legitimidade, de quem ou do que é por ela representado, seja o "povo" ou a vontade absoluta do monarca. Quanto mais o representante estiver afastado do representado, tanto menos carga energética a representação transportará, e tanto mais ela estará sujeita às forças da entropia, ao arrefecimento e à decadência. Qualificar a democracia com o adjetivo representativa é um gesto mais danoso e apolítico do que conceder-lhe o título de liberal ou mesmo de parlamentar. Tal designação quer dizer que este regime subsiste a partir de uma energia emprestada, faltando-lhe uma carga política própria. Se o ímpeto das instituições democráticas foi inicialmente uma discussão vigorosa, onde as relações amigo-inimigo foram transformadas num nexo de adversários que debatiam, esse estímulo (já suspeitoso) que os animava desapareceu agora, dando lugar a uma representação desiludida, cansada e descontente, predicada de uma série de falsas identidades entre os representantes e aqueles que eles representam (SCHMITT, 1986, p. 26).

"A situação do parlamentarismo é hoje crítica", escreve Schmitt na Crise da Democracia Parlamentar, "porque o desenvolvimento da democracia de massas moderna tornou a discussão pública argumentativa numa formalidade vazia. Muitas normas da lei parlamentar 
contemporânea, sobretudo as medidas concernentes à independência dos representantes e à abertura das sessões, tem o resultado de uma decoração supérflua, inútil e mesmo embaraçante, como se alguém tivesse pintado o radiador de um moderno sistema de aquecimento central com chamavas vermelhas para dar a impressão de um fogo em brasas" (SCHMITT, 1986, p. 6). Noutras palavras, a formação dinâmica da energia política foi substituída por uma forma estática ("uma formalidade vazia") de institucionalismo apolítico. Os últimos vestígios de combate, mesmo que apenas numa arena verbal, são eliminados, e o que quer que deles permanece é puramente ornamental, muito como uma representação visual do fogo que Schmitt evoca. A democracia representativa, parlamentar está em crise, precisamente porque se afastou demasiado da fonte do político, da energia fervente que despoleta os agrupamentos amigo e inimigo. A crise, então, não é uma crise da democracia "ela mesma", nem da representação "ela mesma", mas da energia que foi separada daquilo que ela energiza, resultando numa situação em que este se move por inércia e não obedece a nada mais que a lei da entropia.

Por um lado, Schmitt parece acreditar na ficção metafísica da energia como uma pura fonte viva, o significado transcendental de quem ou quê é representado animando o resto do campo político. O mesmo se aplica à sua implícita teoria do conhecimento, a qual, num significativo gesto de platonismo, dá prioridade ao próprio fogo sobre a sua representação desenhada (apesar de a ideia do fogo poder estar aberta à contestação polémica, isto é, política). Daí a crítica: a democracia representativa é uma democracia de energia emprestada, sendo que o emprestar - a representação - se tornou primário e, de facto, definitivo de um regime que ostenta a sua auto-alienação como uma medalha de honra.

No entanto, por outro lado, o político enquanto tal é uma fonte essencialmente impura (diria mesmo "essencialmente não essencial", isto é, existencial), estando as suas origens indefinidamente deslocadas e enterradas em domínios não políticos que podem, de repente, tornar-se politizados. Sempre à margem da des-politização, a energia política reverte para um domínio específico cuja estrutura usual 
temporariamente perverteu; de facto, ela não é senão uma perversão sem um padrão estabelecido de normalidade. A sua inseparabilidade da experiência finita, o subordinar-se, o pathos do político quer dizer que ele é, em igual medida, receptivo e activo, incluindo com respeito às representações presumivelmente baseadas nele. A expressão da sua vitalidade numa relação oposicional, para não falar nos "trabalhos" objetivo e substantivo a que subjaz, e a sua entropia são da mesma natureza. A representação é esta simultaneidade de expressão e entropia dessa energia que não é formalizada a partir de fora, a energia que se dá a si mesma tanto substância como forma enquanto efeito das suas intensidades des-substancializantes.

\section{v.}

As estratégias que Schmitt favorece com vista a poupar energia política (especialmente - embora ele não o veja desta maneira - dela mesma) são multifacetadas. E a maior parte delas são discerníveis no seu livro sobre o catolicismo romano e num ensaio de juventude chamado "A Visibilidade da Igreja". Por um lado, a energia pode ser toda guardada na medida em que não seja expressa, nem representada, mantida numa reserva secreta: "De toda a grande política faz parte o arcanum" (SCHMITT, 1996b, p. 34). Por estranho que possa parecer, a energia política que escapara à expressão e representação não é apenas marginalizada, já não colocando nada em movimento. Pelo contrário, ela anima a política tanto mais vigorosamente, enquanto fica retirada e, portanto, irrepresentada, embora não irrepresentável. Escutando a "mais extrema invisibilidade" de Deus (SCHMITT, 1996b, p. 57), os arcana políticos não são apenas energia detida in potentia, mas são também factores energéticos, as condições de possibilidade da política removidas do campo da visibilidade política.

Uma estratégia relacionada deve permitir à energia uma certa medida de autoexpressão e autorrepresentação, desde que ela não se desvie demasiado do núcleo que se expressa e representa. Isso, do meu ponto de vista, é a base para o famoso conceito de Schmitt da "representação 
a partir de cima". Tal como o Papa é o Vigário de Cristo na Terra, e tal como a Igreja visível é um sinal do reino espiritual invisível ("neste mundo, mas não deste mundo") (SCHMITT, 1996b, p. 52), assim também um representante político é a concreção temporária, o congelamento da energia política que lhe empresta legitimidade e uma "dignidade especial" (SCHMITT, 1996b, p. 21). O desvio desta energia de si mesma é minimizado graças à restrição da representação à expressão, a qual Schmitt liga à personificação quer em Catolicismo Romano quer no seu estudo sobre Thomas Hobbes: "Representar, em sentido eminente, só pode ser feito por uma pessoa, isto é, não simplesmente um 'deputa$\mathrm{do}^{\prime}$, mas uma pessoa com autoridade ou uma ideia que, se for representada, também se torna personificada" (SCHMITT, 1996b, p. 21). Sendo claramente herdada da doutrina da encarnação divina, o personalismo igualmente prevalecente na teoria da soberania de Schmitt é um caso particular de expressão representacional. Aqui, a integridade da energia política é garantida ao articular as suas modalidades verbal e substantiva, o seu operar e a sua obra (ergon), na medida em que esta gera aquele na sua atualidade. $\mathrm{O}$ representante, por seu lado, torna-se um mediador neste processo interno à energia: um médium, por meio do qual, não sendo nem imanente nem absolutamente transcendente à ordem política, a energia condiz o seu comércio consigo mesma.

Em vez de "personificação", Personalisierung, aquilo com que nos deparamos quando se trata da autoexpressão representacional da energia política é figuração, cujas raízes estão mais no mundo da alegoria barroca que no da teologia patrística. Segundo Schmitt, “a Igreja católica é um único exemplo contemporâneo sobrevivente da capacidade medieval para criar figuras representativas - o Papa, o Imperador, o monge, o cavaleiro, o mercador. [...] Ela está tão sozinho que quem quer que nela veja apenas a forma exterior tem de dizer, de forma zombeteira, que ela nada mais representa senão a ideia de representação" (SCHMITT, 1996b, p. 19). Claro está, a "forma exterior" da representação figural é a expressão da forma interior, trazida pelo próprio conteúdo energético. Na dialéctica da autoexpressão política, desenvolvida por Schmitt com pouca referência a Hegel, a figuração é apenas uma configuração de energia detida temporariamente que trata da sua 
própria representação. A dissolução do pensamento figural na modernidade, o seu declínio em face da abstração racional, pressagia a dissipação da energia que ainda é capaz de se agregar nos grupos reconhecíveis dos quais é composta a existência quotidiana. Como regra, com o eclipse da figuração na política, o existencialismo político torna-se insustentável ou, quando ainda é adotado, torna-se numa caricatura atávica, reacionária e marcadamente irracional de uma racionalidade abstrata incorpórea. A racionalidade política infigurada é a realidade política desfigurada e resistente à representação.

Seja qual for a estratégia que Schmitt adota, ele é relutante em relação a passar para o outro extremo, o do economicismo que enfatiza uma total visibilidade, a materialidade e as técnicas de administração. Enfaticamente, ele não é um advogado da pura invisibilidade, de um refúgio puramente espiritual ou de um misticismo ligado ao outro mundo. Seja na forma opaca do arcanum que molda o campo político ou na autoexpressão da representação figural, o visível e o invisível são reconectados numa tentativa de estabelecer um equilíbrio energético precário que conduz à vida (pública). A energia política, tal como a de outros tipos, não é redutível nem a fluxos destituídos de forma, os quais, estando sempre em potência, carecem mesmo de uma atualização momentânea, nem a estruturas institucionais dentro das quais estes fluxos são profundamente congelados. Trata-se, antes, de uma interação em curso entre estes dois momentos, entre os trabalhos invisíveis que pertencem à fé e os trabalhos visíveis (SCHMITT, 1996b, p. 58), entre aquilo que anima e o que é animado, o qual, como os fenomenólogos notam corretamente, precisa de ser incessantemente reanimado, precisa de ser novamente posto em jogo ou posto em movimento. Dito de uma maneira pouco ortodoxa, essa é a lição principal dos escritos de Schmitt acerca da teologia política em geral, e do catolicismo em particular.

\section{Considerações finais}

Como compreenderá um leitor astuto, a crítica da representação expõe Schmitt a um bombardeamento de acusações desconstrutivas, 
incluindo, nas Políticas da Amizade, as do próprio Derrida. No seu todo, o jurista alemão é acusado de uma aliança não tão secreta à metafísica da presença, responsável pela sua predileção por alguns tipos de representação em relação a outros. No entanto, esta interpretação "fácil" é defeituosa não apenas porque descura a impureza originária do político - a sua derivação bastarda de qualquer domínio concebível da atividade humana - mas também porque julga equivocamente o autoposicionamento de Schmitt em relação aos extremos do materialismo e do idealismo, a presença inexorável e a visibilidade das coisas e a invisibilidade das "realidades espirituais". O estatuto da Igreja e, por isso, da forma política a que Schmitt aspira é o de um traço, sendo que a figura estabelecida da desconstrução denota uma ausência presente ou uma presença ausente, o traço de um outro mundo ou de um outro tempo neste mundo e neste tempo. Qualquer representação digna desse nome se atém à figura sem figura do traço, política e ontologicamente.

Escolher a presença em detrimento da ausência é aderir ao economicismo; optar pela ausência em detrimento da presença é cair nas malhas da religião privada (leia-se: do protestantismo), o qual, na verdade, não é assim tão diferente do economicismo, meramente distorcido e repudiado ("Considerada historicamente, a 'privatização' tem a sua origem na religião. [...] A propriedade privada é venerada precisamente porque é uma questão privada") (SCHMITT, 1996b, p. 28). Nenhuma destas alternativas é a pelativa para Schmitt, e nenhuma é compatível com a representação: a primeira, porque nada há para representar onde tudo está idealmente presente; a segunda, porque a "privatização" excessiva elimina a linguagem enquanto tal. As pontas e as mediações que ele se esforça por construir entre estes dois abismos não são substanciais estruturas monumentais. São traços e traçados, figuras frágeis que surgem e se desvanecem num instante histórico.

Por mais importante que o tratamento da representação seja em si mesmo e por si mesmo, ele é especialmente válido por aquilo que diz sobre a energia política. Este conceito também tem sido frequentemente acusado de pertencer ao panteão das noções que - mais ou menos intercambiáveis umas com as outras - sustentam a metafísica da presença. Mas a energia política schmittiana (ou, melhor, o político 
qua energia) é ele mesmo um traço de outros domínios da atividade humana que ele polariza, tanto da substância como do sujeito, de distinções qualitativas e rígidos sistemas de classificação. Sem identidade, conjugando até a diferença entre a estática e a dinâmica, a energia é um traço. Para além das aplicações imediatamente políticas desta conclusão, podemos sentir as suas reverberações tremendas na ontologia depois do fim da metafísica.

\section{Referências}

LE BON, G. The Crowd: A Study of the Popular Mind. New York: Macmillan, 1896.

LE BON, G. The Evolution of Forces. New York: D. Appleton \& Co., 1908.

SCHMITT, C. Political Theology: Four Chapters on the Concept of Sovereignty. Trad. G. Schwab. London and Cambridge: MIT Press, 1985.

SCHMITT, C. The Crisis of Parliamentary Democracy. Trad. E. Kennedy. Cambridge and London: MIT Press, 1986.

SCHMITT, C. The Concept of the Political. Trad. G. Schwab. Chicago and London: The University of Chicago Press, 1996a.

SCHMITT, C. Roman Catholicism and Political Form. Trad. G. L. Ulmen. Westport, CT and London: Greenwood Press, 1996b.

SCHMITT, C. Constitutional Theory. Trad. J. Seitzer. Durham and London: Duke University Press, 2008.

Recebido: 18/04/2017

Received: 04/18/2017

Aprovado: 30/07/2017

Approved: 07/30/2017 